ABDINE: Jurnal Pengabdian Kepada Masyarakat Vol. 1, No.2, Desember 2021,Hal. 72 - 78

p-ISSN 2798-2882, e-ISSN 2798-2890

\title{
Pendampingan Pengembangan Wisata Desa Blarang Kecamatan Tutur Kabupaten Pasuruan
}

\author{
Wisma Soedarmadji ${ }^{1}$, Abdul Wahid ${ }^{2}$ \\ ${ }^{1}$ Program Studi Teknik Mesin, Universitas Yudharta Pasuruan \\ 2Program Studi Teknik Industri, Universitas Yudharta Pasuruan \\ *wisma@yudharta.ac.id, wahid@yudharta.ac.id
}

\begin{abstract}
Abstrak
Blarang village is one of the villages located in the Tutur sub-district, which is at the southwest tip of Pasuruan Regency, which has an area of 612 hectares, and has 5 hamlets, namely Krajan Hamlet, Cemoro Hamlet, Manggungan Hamlet, Banyusari Hamlet, and Pronojiwo Hamlet. Blarang village has potential tourist attractions with interesting natural views including Lawangan hill, Kukusan hill, Suwati mountain, and Responsibility mountain. The Blarang tourist village has not brought in many local tourists continuously (periodically), this is due to many factors such as the infrastructure is not ready and there is no good management system in managing the tourist village so that it can help increase the income of the surrounding community. The purpose of this community service is to provide assistance in the formation of a tourist village guided by the University of Yudharta Pasuruan in Blarang Village, Tutur District, Pasuruan Regency. This service provides socialization and training on web creation. The results of the service are getting community support for the creation of a tourist village because it will have a positive impact on the community's economy, the creation of the Blarang tourist village website.
\end{abstract}

Keywords: Blarang village potential, village tourism assistance, website

\begin{abstract}
Abstrak
Desa Blarang merupakan salah satu desa yang bertempat di wilayah Kecamatan Tutur berada diujung barat daya Kabupaten Pasuruan, yang memiliki luas wilayah 612 heaktar, dan memiliki 5 Dusun yaitu Dusun Krajan, Dusun Cemoro, Dusun Manggungan, Dusun Banyusari, dan Dusun Pronojiwo. Desa Blarang potensi tempat-tempat wisata dengan pemandangan alam yang menarik diantaranya bukit Lawangan, bukit Kukusan, gunung Suwati, dan gunung Tanggung. Desa wisata Blarang belum banyak mendatangkan wisatawan lokal secara kontinu (berkala), hal ini banyak factor penyebabnya seperti infrastruktur belum siap dan belum adanya system manajemen yang baik dalam pengelolan desa wisata sehingga dapat membantu meningkatkan pendapatan masyarakat sekitar. Tujuan pengabdian kepada masyarakat ini melakukan pendampingan dalam pembentukan desa wisata binaan Universitas Yudharta Pasuruan di desa Blarang Kecamatan Tutur Kabupaten Pasuruan. pengabdian ini memberikan sosialisasi dan pelatihan pembuatan web. Hasil pengabdian didapat dukungan masyarakat akan terciptanya desa wisata karena akan berdampak positif pada ekonomi masyarakat, terciptanya website desa wisata blarang.
\end{abstract}

Kata Kunci: Potensi desa Blarang, pendampingan desa wisata, website

\section{PENDAHULUAN}

Desa Blarang merupakan salah satu desa yang bertempat di wilayah Kecamatan Tutur berada diujung barat daya Kabupaten Pasuruan, yang memiliki luas wilayah 612 hektar yang terbagi menjadi 5 Dusun yaitu Dusun Krajan, Dusun Cemoro, Dusun Manggungan, Dusun Banyusari, dan Dusun Pronojiwo. Desa Blarang yang berpenghuni \pm 1342 Kepala Keluarga terdiri dari 5753 Jiwa, dan dikelilingi oleh penggunungan. Hampir $70 \%$ wilayah di Desa Blarang didominasi oleh lahan pertanian. Potensi-potensi yang dimiliki Desa Blarang Kecamatan Tutur Kabupaten Pasuruan selain sektor pertanian, 
Desa Blarang juga memiliki potensi tempat-tempat wisata dengan pemandangan alam yang menarik diantaranya bukit Lawangan, bukit Kukusan, gunung Suwati, dan gunung Tanggung dan potensi wisata tersebut perlu adanya pendampingan dari Universitas Yudharta Pasuruan melalui desa wisata sehingga kedepannya dapat meningkatkan perekonomian masyarakat setempat.

Desa wisata mulai dilirik oleh pemerintah, hal ini dimbangi dengan berkembangnya ide-ide kreatif dalam upaya pengembangan desa wisata (Syah, 2017)(Komariah et al., 2018)(Arif \& Desyanti, 2021). desa wisata merupakan suatu daerah wisata yang tujuan untuk memperkenalkan daya tarik wisata yang disajikan dalam suatu struktur kehidupan masyarakat yang menyatu dengan tata cara dan tradisi yang berlaku (Arida \& Pujani, 2017). Desa wisata sekarang ini telah banyak bermunculan tapi tidak banyak pula yang berhasil mendatangkan wisatawan secara kontinu (berkala), hal ini banyak factor penyebabnya seperti infrastruktur belum siap dan belum adanya system manajemen yang baik dalam pengelolan desa wisata (Anis Nurhayati, 2020) .

Desa blarang memiliki berbagai eksotik pemandangan alam yang masih belum terkelola dengan baik ada yang namanya gunung Lawangan, Bukit Kukusan, Gunung Tanggung dan Gunung Suwati yang mana semua itu bisa diligat pada Gambar 1.

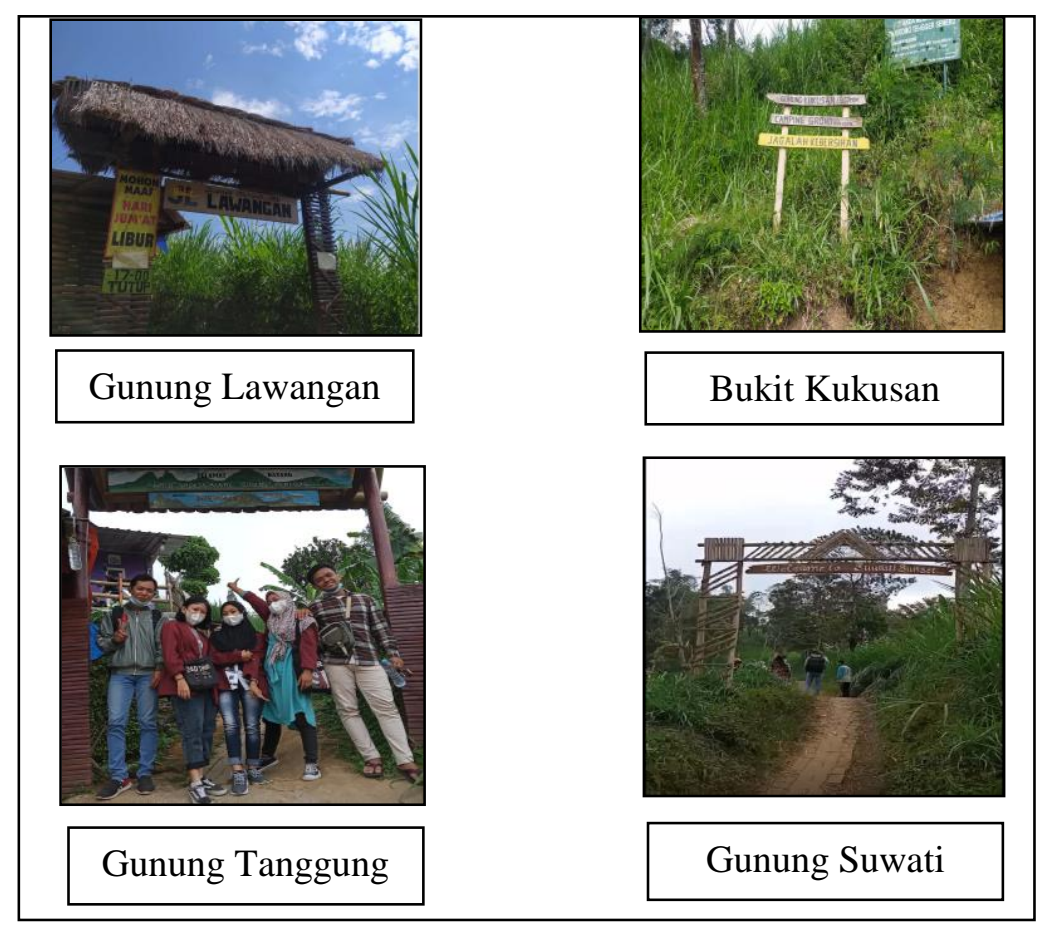

Gambar 1. Identifikasi Desa Wisata Blarang

Wisata pedesaan yang berbasis potensi alam, pertanian, sosial dan budaya lokal bisa menjadi pengembangan potensi masyarakat berbasis wisata (Lestari, 2019). Pemikiran Bagus, 2018 bahwa daya tarik dan keunikan suatu desa dengan alam pedesaan yang dikelola, dikemas dengan menarik serta pengembangan fasilitas pendukung wisata ditata dalam satu lingkungan yang harmonis. Indriyani et.al 2018 bahwa pengembangan desa wisata dapat dijadikan salah satu sumber pendapatan tambahan bagi desa dan masyarakat 
ABDINE: Jurnal Pengabdian Kepada Masyarakat Vol. 1, No.2, Desember 2021,Hal. 72 - 78

p-ISSN 2798-2882, e-ISSN 2798-2890

(Dailiati:2018), peluang ini dapat ditangkap oleh pemerintah desa dan masyarakatnya, yang dapat berdampak pada peningkatan ekonomi melalui pengembangan desa wisata. Manfaat pengembangan desa wisata banyak dirasakan baik disektor ekonomi, sosial, pendidikan, iptek, sosial budaya, dan lingkungan (Nur et al., 2018). Sektor ekonomi, desa wisata dapat meningkatkan perekonomian masyarakat lokal, Dengan memacu potensi tumbuhnya ekonomi kreatif, di mana warga bisa membuat souvenir dan aneka kerajinan tangan yang memiliki nilai jual tinggi Sektor Sosial, dapat membuka lapangan kerja bagi warga setempat dan karang taruna sebagai pemandu wisata sehingga memperoleh penghasilan tetap. Desa Blarang sendiri mempunyai potensi wisata dengan pemandangan alam yang menarik diantaranya Bukit Lawangan, Bukit Kukusan, Gunung Suwati, Dan Gunung Tanggung. Potensi wisata itu perlu dikembangkan, mengingat pemandangan alamnya sangat indah dan eksotik.

\section{Metode}

Metode pelaksanaan pengabdian masyarakat ini menggunakan pendekatan Asset Based Community Development atau disebut dengan metode ABCD. Metode ini digunakan untuk pendekatan pendampingan kepada masyarakat dan mengupayakan memberikan wawasan dalam pemikiran masyarakat harus dilaksanakan dengan sejak dari awal. Pendekatan ABCD merupakan pendekatan yang mengarah pada pemahaman dan internalisasi asset, potensi, kekuatan, dan pendayagunaannya secara mandiri dan maksimal.

Langkah awal yang dilakukan dalam proses pengembangan tersebut adalah bagaimana kapasitasnya dengan melihat keterampilan dan pengalaman yang dimiliki individu tersebut. Setelah langkah awal dilakukan proses selanjutnya yaitu saling memberikan dukungan antar individu, komunitas, lalu tahap terakhir selaku warga negara kita harus melakukan proses ini bersama-sama demi kepentingan bersama dan mencapai tujuan yang diharapkan.

Pengembangan masyarakat berbasis aset menjadikan kekuatan, anugerah, bakat, dan segala sumber baik yang dimiliki individu maupun komunitas dan bisa menolong komunitas untuk memobilisasi, membangun aset tersebut untuk pembangunan yang berkelanjutan.

Pengembangan masyarakat berbasis komunitas adalah pendekatan yang berfokus pada menemukan dan memobilisasi sumber daya yang tersedia dalam komunitas. Pendekatan Asset Based Community Development menyediakan sebuah cara bagi masyarakat untuk menemukan dan memobilisasi aset yang mereka miliki untuk menjadi komunitas yang kuat.

\section{Pembahasan}

Pelaksanaan program pengabdian ini diikuti oleh 21 mahasiswa/i lintas program studi dalam pengembangan Desa Wisata di Desa Blarang Kecamatan Tutur sekaligus sebagai implementasi desa binaan Universitas Yudharta Pasuruan yang telah dilakukan MOU terlebih dahulu dengan desa setempat. Selama masa pandemik pelaksanaan program pengabdian masyarakat menggunakan system pendekatan blended/campuran antara pelaksanaan online dan offline serta tetap mengacu dan menerapkan pada protokol kesehatan. Hasil kegiatan pendampingan masyarakat dalam pengembangan desa wisata di desa Blarang Kecamatan Purwodadi Kabupaten Pasuruan ini antara lain berupa FGD (Forum Grup Discusstion), Pembuatan website wisata. 
ABDINE: Jurnal Pengabdian Kepada Masyarakat Vol. 1, No.2, Desember 2021,Hal. 72 - 78 p-ISSN 2798-2882, e-ISSN 2798-2890

\section{a. Forum Grup Discusstion (FGD)}

FGD dilaksanakan selama beberapa kali yang bertujuan untuk menggali dan menemukan potensi desa yang spesifik (Yandra:2021) tetapi masih belum tampak yang di dapatkan di lapangan pada saat dilakukan observasi, sehingga dengan FGD ini dihahardan mampu mendesain wisata yang akan dibentuk. Dalam kegiatan FGD membahas terkait nama desa wisata, peluang dan tantangan desa wisata, pembuatan website desa wisata.
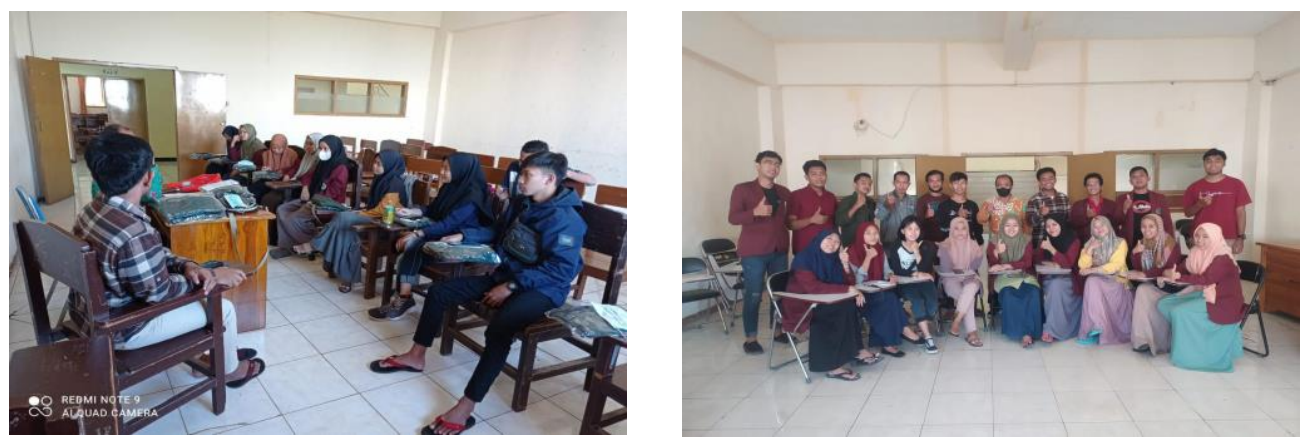

Gambar 2. Forum Group Discusstion (FGD)

Langkah selanjutnya dilakukan proses pengumpulan data dengan menggunakan langkah-langkah lanjutan diantaranya.

-. Obervasi

Teknik pengumpulan data yang dilakukaan melalui suatu pengamatan, dengan disertai pencatatan-pencatatan terhadap suatu potensi wisata yang ada di Desa Blarang Kecamatan Tutur. Di dapatkan lokasi yang dapat mendukung objek wisata.

- Wawancara

Pertemuan yang dilakukan oleh 10 warga stempat untuk bertukar informasi maupun suatu ide dengan cara tanya jawab sehingga mendapatkan informasi seberapa stuju sampai tidak setuju sehingga menjadi sebuah maskukan awal untuk di lanjutkan kegitan ini yang mana data tersebut dapat di lihat pada gambar 3.

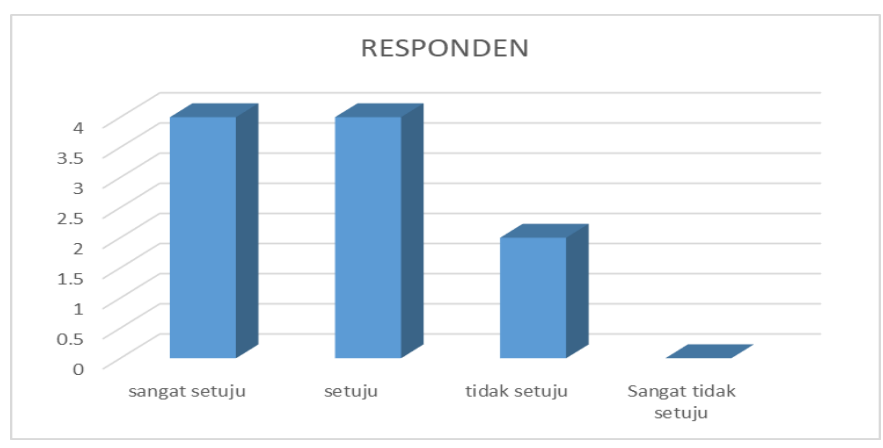

Gambar 3. Data Responden 
ABDINE: Jurnal Pengabdian Kepada Masyarakat Vol. 1, No.2, Desember 2021,Hal. 72 - 78 p-ISSN 2798-2882, e-ISSN 2798-2890

Dokumentasi

Dokumentasi ini digunakan agar bisa mendapatkan data yang dibutuhkan secara cepat, tepat dan akurat pada saat kita melakukan observasi dan wawancara, hal ini dapat berupa foto, gambar.
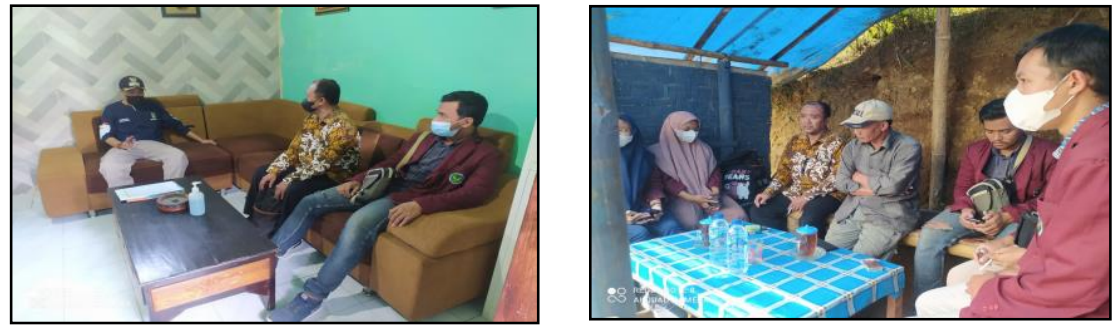

Gambar 4. Proses pengumpulan informasi dan data

\section{b. Pembuatan Website Desa Wisata Blarang}

Website merupakan suatu wadah informasi yang dapat diakses secara online oleh kalangan banyak orang (Samantha \& Almalik, 2019). Pembuatan website desa wisata Blarang dilaksanakan secara bertahap, mulai dari penentuan nama domain (www.blarang.com), pembelian hosting, desain template, mengisi konten potensi desa wisata blarang sampai dengan publikasinya. Penerapan teknologi informasi dalam pengelolaan pariwisata di desa Blarang Kecamatan Tutur Kabupaten Pasuruan adalah merupakan pengembangan aplikasi website desa wisata Blarang sebagai media informasi, keberadaan website memiliki manfaat yang luas bagi pengelola maupun penggunanya dengan melibatkan masyarakat untuk membuat profil desa dan destinasi wisata yang ada di Desa Blarang.
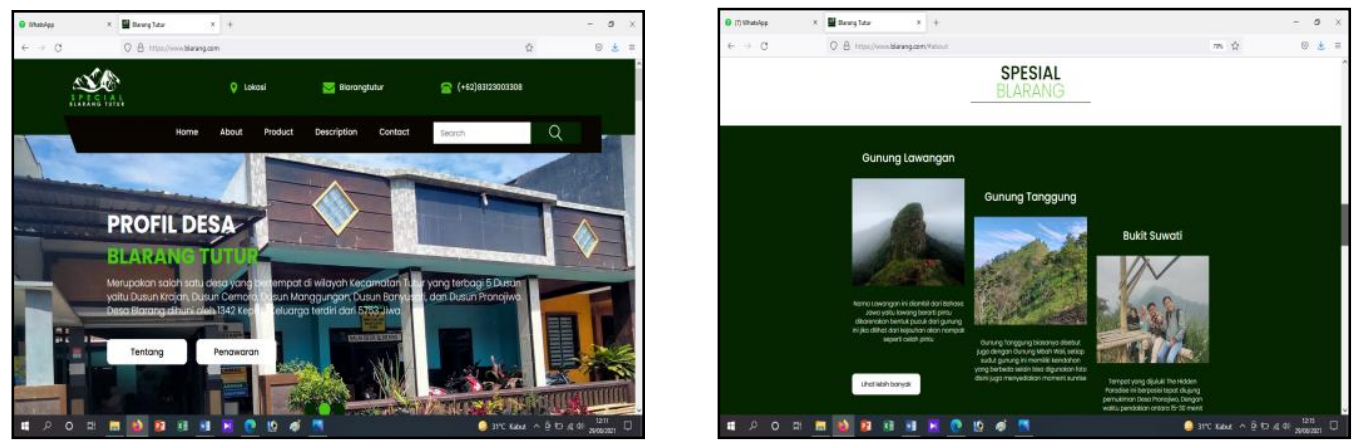

Gambar 5. Tampilan Website Wisata Desa Blarang
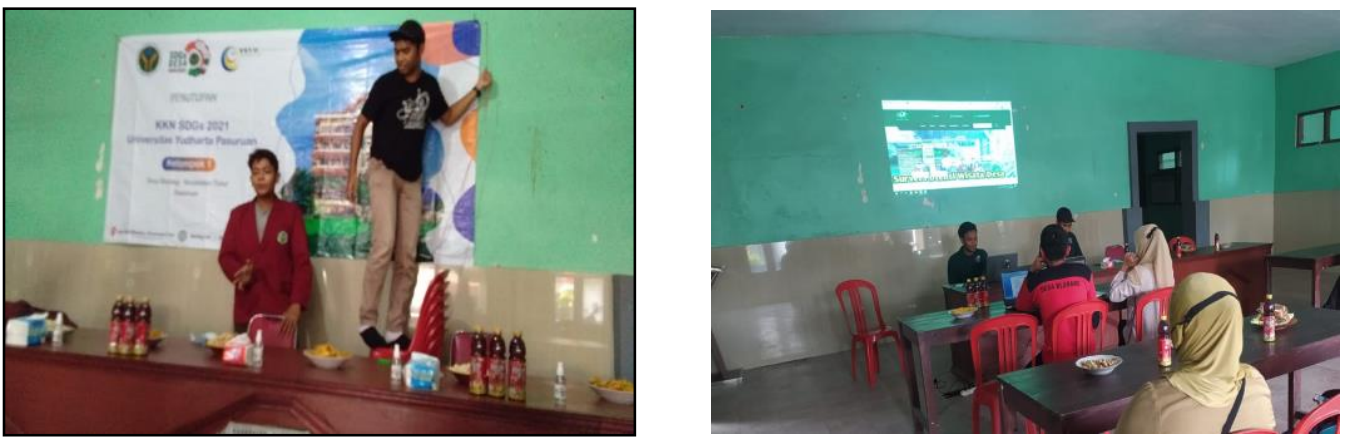

Gambar 6. Sosialisasi dan Pelatihan Website Wisata Desa Blarang 
ABDINE: Jurnal Pengabdian Kepada Masyarakat Vol. 1, No.2, Desember 2021,Hal. 72 - 78 p-ISSN 2798-2882, e-ISSN 2798-2890

Dalam kegiatan ini masyarakat baik dari kalangan pemuda orang tua sampai ibu rumahtanggga sangat antusias dalam mengikuti kegitan baik penyluhan desa wisata dan pada pembutan website Wisata Desa Blarang dan pembentukan komunitas pemuda wisata, sehingga dalam hal ini kegiatan ini sagat membantu dalam peningkatan destinasi wisata yang dapat di kenalkan melalui baik melalui personal maupun melalui media sosial.

\section{KESIMPULAN}

Hasil luaran dari pelaksanaan pengabdian ini adalah dapat mengatasi permasalahan yang dihadapi oleh Desa Blarang. Sehingga dimulai dari kesaadaran masyarakat Desa Blarang dapat tercapai dengan memahai potensi wisata yang ada di Desa Blarang denga membuat kelompok pengembang wisata, menciptkan desain wisata, serta di dukung dengan sosialisasi dan pelatihan pengelolaan website yang di adakan pendampingan dari Universitas Yudharta Pasuruan yang ada di Blarang Kecamatan Tutur Kabupaten Pasuruan, sehingga masyarakat luar daerah baik domestik maupun internasional dapat mengakses dengan mudah destinasi wisata yang ada di Desa Blarang Kecamatan Tutur Kabupaten Pasuruan.

\section{DAFTAR PUSTAKA}

Anis Nurhayati, D. (2020). Pemberdayaan Ekonomi Masyarakat Kelompok Tani Salak Melalui Pelatihan Pengolahan Buah Salak di Desa Brambang Kecamatan Gondangwetan Kabupaten Pasuruan. 2.

Arida, I. N. S., \& Pujani, L. K. (2017). Kajian Penyusunan Kriteria-Kriteria Desa Wisata Sebagai Instrumen Dasar Pengembangan Desawisata. Jurnal Analisis Pariwisata, 17(1), 1-9.

Arif, M., \& Desyanti, D. (2021). Pelatihan Kewirausahaan Bina Bisnis Pembuatan Pot Bunga Kekinian Untuk Masyarakat Perumahan Baruna. ABDINE: Jurnal Pengabdian Masyarakat, 1(1), 8-13. https://doi.org/10.52072/abdine.v1i1.160

Dailiati, S., \& Yandra, A. (2018, May). Tourism and Environmental Policy Strategies: Promoting Local Destination in Riau Province. In IOP Conference Series: Earth and Environmental Science (Vol. 156, No. 1, p. 012061). IOP Publishing.

Komariah, N., Saepudin, E., \& Yusup, P. M. (2018). Pengembangan Desa Wisata Berbasis Kearifan Lokal. Jurnal Pariwisata Pesona, 3(2), 158-174. https://doi.org/10.26905/jpp.v3i2.2340

Lestari, R. A. (2019). Dinamika Governance. Dinamika Governance: Jurnal Ilmu Administrasi Negara, 9(1).

Nur, I., Mariantha, I. N., Syafri, \& Faridah. (2018). Implikasi pengembangan desa wisata terhadap peningkatan ekonomi masyarakat lokal (studi di Desa Pao). Seminar Nasional Dan Call for Paper: Manajemen, Akuntansi Dan Perbankan 2018, 1090-1104.

Samantha, R., \& Almalik, D. (2019). Rancang Bangun Website Desa Kresek-Madiun Untuk Media Informasi Potensi Wisata Alam Dan Kulinier. Tjyybjb.Ac.Cn, 3(2), 58-66. http://www.tjyybjb.ac.cn/CN/article/downloadArticleFile.do?attachType=PDF\&id=9987

Syah, F. (2017). Strategi mengembangkan desa wisata. Seminar Nasional Multi Disiplin Ilmu Ke-3(Sendi_U 3) 2017, 3(Sendi_U 3), 335-341.

Yandra, A., Nielwaty, E., Herlinda, D., \& Faridhi, A. (2021). Pendidikan Politik Dan Civic 
ABDINE: Jurnal Pengabdian Kepada Masyarakat Vol. 1, No.2, Desember 2021,Hal. 72 - 78 p-ISSN 2798-2882, e-ISSN 2798-2890

Culture Pada Ibu-Ibu Pembinaan Kesejahteraan Keluarga (PKK). ABDINE: Jurnal Pengabdian Masyarakat, 1(1), 56-62. 